\title{
Tying Processing Parameters to the Microstructure and Mechanical Properties of Nanostructured FeNiZr Consolidated via the Field Assisted Sintering Technique
}

\author{
Sean J. Fudger ${ }^{1, *}$, Thomas L. Luckenbaugh ${ }^{2}$, Anthony J. Roberts ${ }^{1}$, Chris D. Haines ${ }^{1}$ \\ and Kris A. Darling ${ }^{1}$ \\ 1 U.S. Army Research Laboratory, Weapons and Materials Research Directorate, Aberdeen Proving Ground, \\ MD 21005-5069, USA; anthony.j.roberts69.civ@mail.mil (A.J.R.); christopher.d.haines2.civ@mail.mil (C.D.H.); \\ kristopher.a.darling.civ@mail.mil (K.A.D.) \\ 2 Bowhead Total Enterprise Solutions, LLC, 4900 Seminary Road, Suite 1200, Alexandria, VA 22311, USA; \\ thomas.l.luckenbaugh.ctr@mail.mil \\ * Correspondence: sean.j.fudger.civ@mail.mil; Tel.: +1-410-306-0965
}

Received: 28 February 2019; Accepted: 11 April 2019; Published: 13 April 2019

\begin{abstract}
An oxide-dispersion-strengthened (ODS) nanostructured FeNiZr alloy was fabricated via high energy mechanical alloying, and subsequently consolidated by the field assisted sintering technique (FAST). A range of input parameters: Temperature, hold time and pressure were evaluated in an effort to optimize the mechanical response of the material. Improvements in density, up to $98.6 \%$ of theoretical, were observed with increasing consolidation temperature and hold time at the cost of decreasing hardness values resulting from microstructural coarsening. Hardness values decreased from 650 to $275 \mathrm{HV}$ by increasing processing temperatures from 750 to $1100{ }^{\circ} \mathrm{C}$. The relationships between the varied processing parameters, microstructure and the experimentally measured yield and ultimate tensile strengths are discussed. Specifically, the effect of varying the temperature and hold time on the resulting porosity, as observed via scanning electron microscopy (SEM) in tensile and compression samples, is emphasized.
\end{abstract}

Keywords: oxide-dispersion-strengthening; nanocrystalline; spark plasma sintering; metals

\section{Introduction}

Owing to the exceptional strength, creep and fatigue properties in addition to thermomechanical stability and irradiation resistance, oxide-dispersion-strengthened (ODS) alloys were initially designed for nuclear reactor applications [1-13]. These outstanding mechanical properties, capable of a wide range of operating temperatures, offer superior performance in a number of environmental conditions. This unique combination of properties appears useful for Army applications in light-weighting the soldier and/or vehicles while increasing their protection and improving lethality for munitions and weapons platforms.

High energy mechanical alloying was utilized as a means of creating ultra-fine nano-particle dispersions. These resulting $\mathrm{Zr}$ based nano-scaled oxides and/or coherent oxide clusters are partially responsible for the increased strength, in addition to the grain refinement and resulting Hall-Petch strengthening. Darling et al. performed transmission electron microscopy (TEM) and atom probe tomography (APT) on equal channel angular extruded (ECAE) material of the same chemistry and mechanical alloying method, confirming oxide-based precipitates ranging in size from $2.3-4 \mathrm{~nm}$ based on processing temperatures between 700 and $1000^{\circ} \mathrm{C}$ [1]. The high number density (particle densities of 
$\sim 10^{23} / \mathrm{m}^{3}$ ) of coherent/semi-coherent oxide particles or clusters has been identified as the main source of the enhanced microstructural thermal stability observed with these ODS alloys [1,14]. A discontinuous distribution of fine oxide particles throughout an alloy matrix works to efficiently obstruct dislocations movement and impede grain boundary motion, specifically at elevated temperatures and while the material is being deformed [15]. While much attention in preparing and processing ODS alloys has focused on yttria, Darling et al. have proven the use of zirconia to be an effective alternative resulting from the following: Zirconium has a high affinity for oxygen, resulting in the ability to form oxides. Oxides based from $\mathrm{Zr}$ have higher melting temperatures than those of $\mathrm{Y}$. $\mathrm{Zr}$ has a low mobility resulting from a large atomic mismatch between $\mathrm{Zr}$ and the Fe matrix. Doping $\mathrm{Zr}$ with Fe stabilizes the high temperature cubic phase, which increases the chance of attaining coherency with the Fe matrix by resizing the unit cell [1]. Previous work indicates $\mathrm{Fe}_{91}-\mathrm{Ni}_{8}-\mathrm{Zr}_{1}$ (at. \%) provides microstructural stability up to $700{ }^{\circ} \mathrm{C}$ [14]. While larger additions of $\mathrm{Zr}, 3$ and 4 at. \%, have been shown to provide increased stability up to 800 and $900^{\circ} \mathrm{C}$, respectively, the corresponding strength and ductility decrease compared with the 1 at. $\% \mathrm{Zr}$ alternative.

The field assisted sintering technique (FAST) or spark plasma sintering (SPS) combines simultaneous application of mechanical, thermal and electrical energies in the form of applied pressure, temperature and pulsed electric current. This process allows for a one-step consolidation of materials, many reaching near $100 \%$ theoretical density in a very short time. As a result of the conductive nature of the powder and the materials used for tooling, low voltages (generally below $10 \mathrm{~V}$ ) are required resulting in extremely high currents (5-30 kA) passing directly through the powder. This results in Joule heating in the powder and is responsible for the rapid heating rate of the material, up to $1000^{\circ} \mathrm{C} / \mathrm{min}$, without requiring an external thermal source [16]. These rapid heating rates and overall shorter processing times compared to traditional consolidation processes, hot isostatic pressing or hot extrusion, help minimize microstructural coarsening and subsequent decreases in strength. Since grain boundary diffusion (one of the primary densification mechanisms) has a higher activation energy than surface diffusion (a coarsening mechanism) rapid heating rates help impede grain growth thus maximizing the Hall-Petch strengthening mechanism [17].

Previous work indicates the grain growth process in $\mathrm{Fe}_{91} \mathrm{Ni}_{8} \mathrm{Zr}_{1}$ initiates at the early stages of high temperature processing, followed quickly by stagnation within only a few minutes. The resulting mechanical properties remain remarkably high despite micrometer-sized grains forming after long-term annealing and consolidation at high temperatures. This indicates that the kinetics of particle coarsening are sluggish, allowing the retention of elevated properties despite long-term exposure to high temperatures [18].

In the present work, FAST is being evaluated as a practical method to consolidate the $\mathrm{Fe}_{91} \mathrm{Ni}_{8} \mathrm{Zr}_{1}$ alloy into a bulk material while maintaining its advantageous properties, many of which are attributed to its ultrafine grained microstructure. Additionally, empirical relationships between the processing parameters, observed microstructure and the resulting mechanical properties are summarized. Density values of up to $98.6 \%$ of theoretical were obtained under a number of FAST processing conditions, however, hardness values and other mechanical properties vary significantly with time and temperature.

\section{Materials and Methods}

\subsection{Mechanical Alloying}

The $\mathrm{Fe}_{91}-\mathrm{Ni}_{8}-\mathrm{Zr}_{1}$ (at. \%) alloy was synthesized by high energy mechanical alloying in a $\mathrm{ZOZ}$ CM08 rotary ball mill (Zoz GmbH, Wenden, Germany). 800 grams of raw Fe, Ni and Zr starting powder, -325 mesh and 99.9\%, 99.9\% and 99.5\% pure (American Elements, American Elements and Materion, respectively) was loaded into a rotary mill with a 10:1 ball to powder mass ratio of $1 / 4^{\prime \prime}$ stainless steel balls. The mixture was then milled for $30 \mathrm{~h}$ at sub-zero temperatures, to limit cold welding, resulting in a homogeneous un-agglomerated powder with individual particle sizes between 5 and $100 \mu \mathrm{m}$. The as-milled grain size of nanocrystalline $\mathrm{Fe}_{91} \mathrm{Ni}_{8} \mathrm{Zr}_{1}$ was found to be around $15 \mathrm{~nm}$ 
using the Scherrer method [18,19]. The milling vials were emptied in a glove box and transferred to air tight containers to be sealed until the powder was ready for sintering.

\subsection{FAST Consolidation}

The resulting milled powders, free of any additives, were put into a $40 \mathrm{~mm}$ cylindrical carbon-carbon composite die lined with GRAFOIL and pre-compacted with a $4500 \mathrm{~kg}$ load. Subsequently, the powders were sintered in an SPS furnace: FCT HP D 125 (FCT Systeme GmbH, Rauenstein, Germany). The consolidation cycle was initiated by evacuating the chamber and applying a $20 \mathrm{kN}$ preload. The powder was then preheated from room temperature up to $450{ }^{\circ} \mathrm{C}$, the minimum reading temperature of the optical pyrometer. Rather than using a constant ramp rate for all processing temperatures, a four minute ramp was performed, increasing the powder temperature from $450{ }^{\circ} \mathrm{C}$ to the maximum processing temperature. Consistent for all samples, once the maximum temperature was reached, the sample was consolidated under an applied pressure of $100 \mathrm{MPa}$. A processing matrix was evaluated varying the processing temperature between 700 and $1100{ }^{\circ} \mathrm{C}$ (approximately 0.5 and 0.75 of the homologous temperature) in $50^{\circ} \mathrm{C}$ increments. In addition, hold times of 5, 10, 30, 45 and $60 \mathrm{~min}$ were used at each processing temperature. Following the described hold time, the pressure was released and the sample was allowed to cool under vacuum in the chamber. The resulting samples were $40 \mathrm{~mm}$ diameter right circular cylinders with an approximate thickness of $10 \mathrm{~mm}$ based on 100 grams of starting powder.

\subsection{Characterization}

The FeNiZr samples were sand blasted and ground to remove any remaining GRAFOIL from the surface, and subsequently measured for density using the Archimedes technique. The theoretical density of the raw powder was $7.91 \mathrm{~g} / \mathrm{cm}^{3}$ based on the ratio of elemental constituents. The samples were polished from 320 to 1200 grit using silicon carbide paper, and subsequently polished with 3 and $1 \mu \mathrm{m}$ diamond slurries. Vickers micro-hardness tests were performed using a Wilson Tukon 1202 (Buehler, Lake Bluff, IL, USA) with a Vickers diamond indenter using a $200 \mathrm{~g}$ load and dwell time of $10 \mathrm{~s}$. Indents were performed selectively within well-defined particles to avoid boundaries and porosity concentrations. The reported hardness datum was an average, calculated by taking 10 individual indents on each sample with the respective error bars representing the standard deviation. Microscopy was performed on a Nova NanoSEM 600 scanning electron microscope (FEI, Hillsboro, OR, USA) at $20 \mathrm{keV}$ in secondary and backscattered electron modes to evaluate the porosity, grain size and consolidation characteristics. Additionally, electron backscattered diffraction (EBSD) was performed to characterize grain size and orientation observed within each sample condition.

\subsection{Sample Fabrication and Mechanical Testing}

The samples were then sliced radially via a wire electrical discharge machine (EDM) to produce a thin wafer with an approximate thickness of $3 \mathrm{~mm}$. These wafers were subsequently milled to produce tension and compression specimens for mechanical testing. All testing was performed at room temperature, $\sim 25{ }^{\circ} \mathrm{C}$, with tensile and compression strain rates of $8 \times 10^{-4} / \mathrm{s}$ and $3 \times 10^{-4} / \mathrm{s}$, respectively. A bowtie-shaped geometry with $9 \mathrm{~mm}$ overall length, $1 \mathrm{~mm}$ gauge width and $400 \mu \mathrm{m}$ thickness was used for tension testing. A full description of specimen geometry and equivalent testing fixture can be found elsewhere $[20,21]$. Right circular cylinders with $\sim 3 \times 3 \mathrm{~mm}$ were tested in compression on an Instron model 55R1125 load frame with a calibrated 10,000 lb load cell. Compression sample fabrication and testing were performed in the axial direction (of FAST consolidation) whereas, due to the height restrictions, tension specimens were limited to fabrication in the radial direction. However, the mechanical behavior of materials fabricated via SPS, namely strength and elongation, was expected to be isotropic [13,22]. VIC-2D Digital image correlation (DIC) was used on both tension and compression samples to measure the strain to failure. Additional microscopy was performed on 
the fracture surface of select tension samples to identify the failure mechanisms observed during brittle and ductile fractures.

\section{Results}

Bulk quantities of the $\mathrm{Fe}_{91}-\mathrm{Ni}_{8}-\mathrm{Zr}_{1}$ powder were successfully synthesized with the ZOZ CM08 rotary ball mill. Subsequently, the powders were efficaciously consolidated with FAST/SPS. Temperature and hold time were manipulated during consolidation in an effort to achieve full density. An applied pressure of $100 \mathrm{MPa}$ was used for all samples to isolate the effects of temperature and hold time. Figure 1 shows the effect of consolidation hold time and processing temperature on the resulting theoretical density and hardness values. Experimental measurements are reported from the bulk as processed materials with trend lines for clarity and error bars where appropriate.

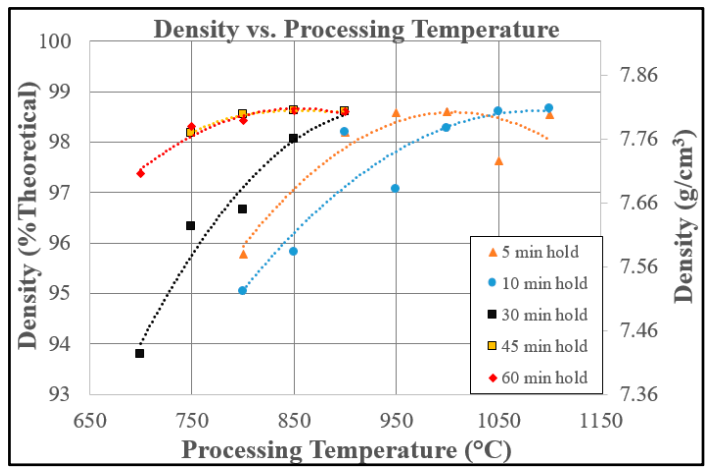

(a)

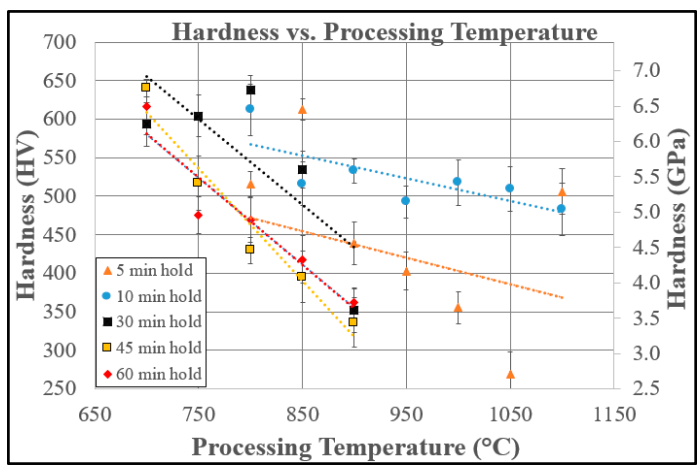

(b)

Figure 1. Experimentally measured density (a) and hardness (b) values as a function of processing temperature and hold time.

As evident from Figure 1, even a modest consolidation temperature of $750{ }^{\circ} \mathrm{C}$ with FAST is capable of producing parts with densities in excess of $98 \%$. The general trend shows increasing hold time and temperature tends to increase the achieved density. It can be seen that a number of conditions produce density values reaching $98.6 \%$ which represents a substantial step towards achieving full density. However, $98.6 \%$ appears to be the upper limit achievable under this range of conditions. In the initial stages of densification, particle rearrangement and necking occur with minimal grain growth. As the bulk density approaches $\sim 90 \%$ there is a shift in porosity from having interconnected to closed pores [23]. Subsequently, the rate of densification slows and grain growth accelerates with time. The grain coarsening associated with increasing processing temperatures and hold times is reflected in the corresponding hardness values in Figure 1. The retained ultrafine grained structure is responsible for the hardness values exceeding $575 \mathrm{HV}$ for each of the $700{ }^{\circ} \mathrm{C}$ processing conditions, as provided by Hall-Petch strengthening. The strengthening contribution provided by the Hall-Petch effect can be seen in Equation (1) below [24,25]. Where $H_{\mathrm{HP}}$ is the strengthening contribution from the Hall-Petch, $H_{0}$ is the starting stress for dislocation movement (material specific), $k$ is the strengthening coefficient (material specific), and $d$ is the average grain diameter.

$$
H_{\mathrm{HP}}=H_{0}+k d^{-1 / 2}
$$

It is clear that the grain growth occurs throughout the full temperature range and the corresponding hardness values decrease independent of hold time. The slope of the hardness vs. temperature curves for the 45 and 60 min conditions appear to be the steepest, confirming increased processing time, in addition to temperature, results in grain coarsening.

Figure 2 presents backscattered electron images collected from bulk samples consolidated at $750{ }^{\circ} \mathrm{C}$, with hold times of 30 and $60 \mathrm{~min}$. The images indicate what appears to be regions of significant levels of interparticle porosity (high concentration of black dots) within each of the processing conditions. 
These regions represent the more severe areas of observed porosity in the bulk material (as indicated in Figure $2 \mathrm{~d}$ ), however, no substantial radial gradients were observed on any of the $40 \mathrm{~mm}$ samples.
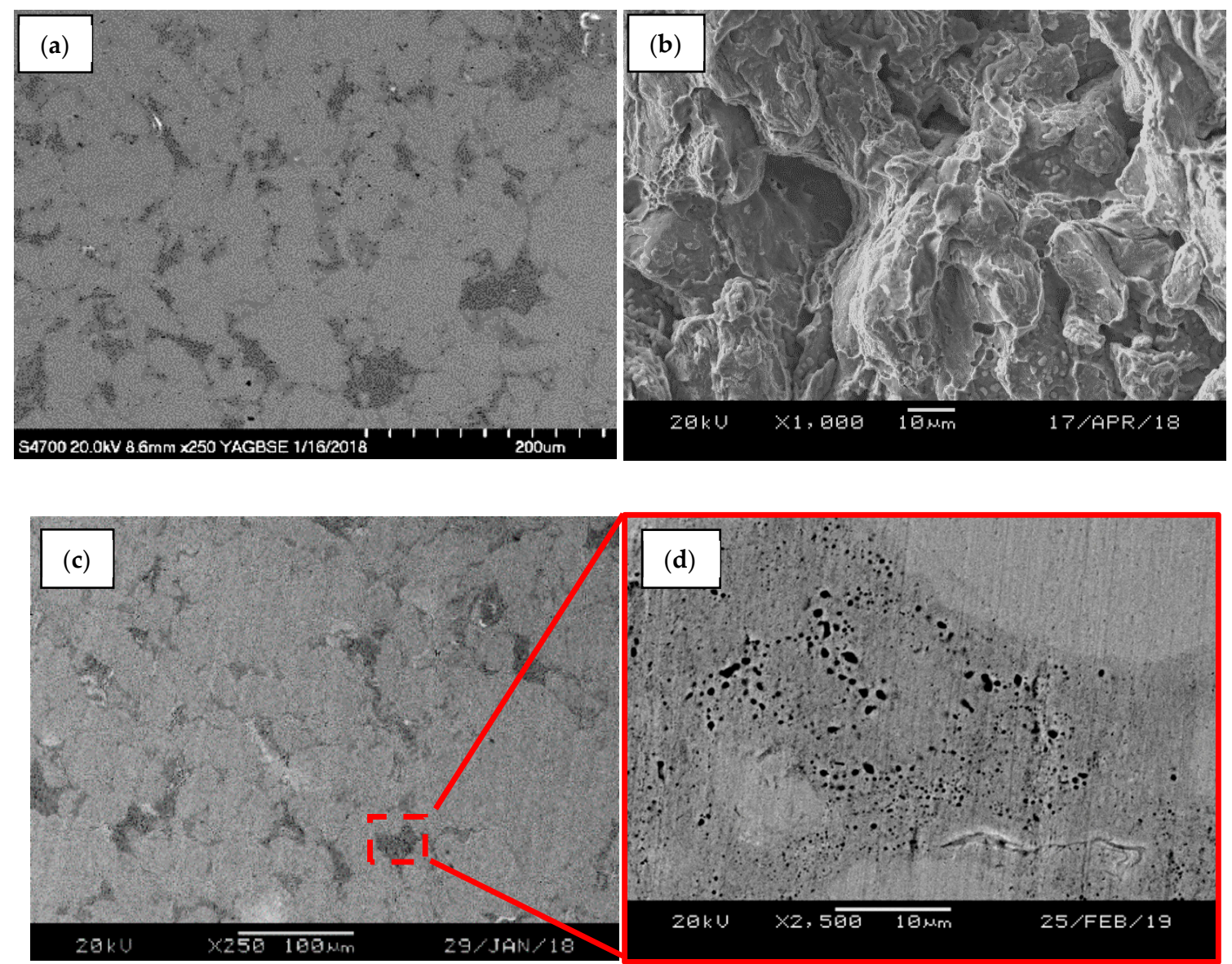

Figure 2. SEM images of field assisted sintering technique (FAST) consolidated $\mathrm{Fe}_{91}-\mathrm{Ni}_{8}-\mathrm{Zr}_{1}$ samples under the following processing conditions and preparation type: (a) $750{ }^{\circ} \mathrm{C}-30 \mathrm{~min}$-polished, (b) $750{ }^{\circ} \mathrm{C}-30 \mathrm{~min}$-fracture surface $(\mathbf{c}, \mathbf{d}) 750{ }^{\circ} \mathrm{C}-60 \mathrm{~min}$ - polished.

Consistent with the measured density values, the observed porosity decreases (from left to right) with increasing consolidation time at $750{ }^{\circ} \mathrm{C}$. As all three conditions exhibit a closed pore structure, grain growth can be expected to continue temporally. Figure $2 \mathrm{~b}$ illustrates a secondary electron image of one fracture surface of the $750{ }^{\circ} \mathrm{C}-30 \mathrm{~min}$ sample tested in tension. The fracture surfaces of all samples processed at $750{ }^{\circ} \mathrm{C}$ in the range of 30 to 60 min exhibit a mostly brittle morphology with some small pockets of ductility in the form of microvoid coalescence. The increased porosity volume fraction or concentrated areas of interparticle porosity near the particle boundaries weaken the bulk material and can act as regions of crack nucleation, as evident from the horizontal crack observed in Figure $2 \mathrm{~d}$.

Figure 3 illustrates EBSD patterns collected on select samples following SPS. As shown in Figure 3, the microstructure of both conditions appears to be isotropic where no apparent texturing exists. A bimodal distribution can be seen where the majority of grains fall into the ultrafine range, but a substantial area fraction of grains have grown abnormally to exceed $10 \mu \mathrm{m}$ in diameter. This abnormal grain growth has been characterized previously as a result of the bcc to fcc phase transformation occurring at approximately $750{ }^{\circ} \mathrm{C}$ in this alloy $[18,26]$. $\mathrm{Fe}_{91}-\mathrm{Ni}_{8}-\mathrm{Zr}_{1}$ is thermally stable up to temperatures of approximately $600{ }^{\circ} \mathrm{C}$, maintaining a grain size below $15 \mathrm{~nm}$ as determined by $X$-ray analysis [14]. An increase in grain size can be observed with the increase in hold time, which corresponds to a decrease in hardness from approximately 600 to $475 \mathrm{HV}$, as shown in Figure 1. This observed hardness shift is in agreement with the compressive yield stress values following Tabor's 
empirical relationship $(H \approx 3 \sigma)[27,28]$. The effect of consolidation hold time on the yield and ultimate tensile stresses is illustrated in both tension and compression in Figure 4.

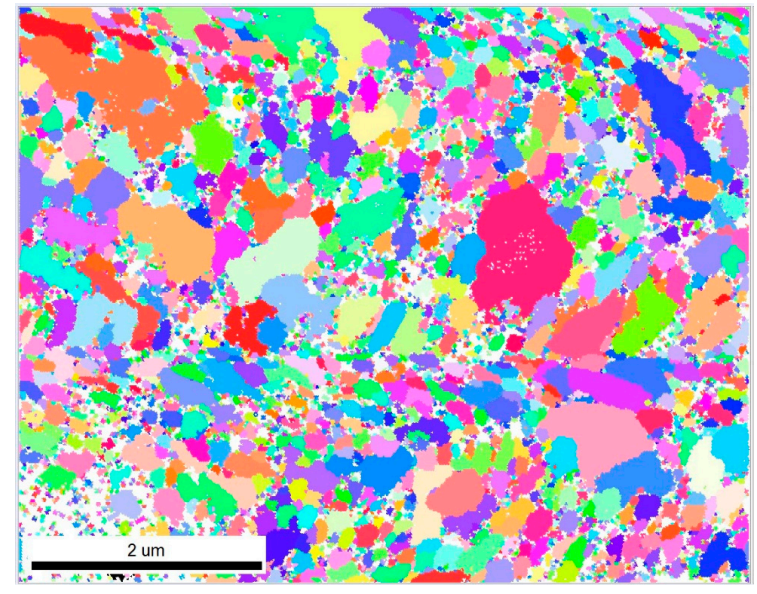

(a)

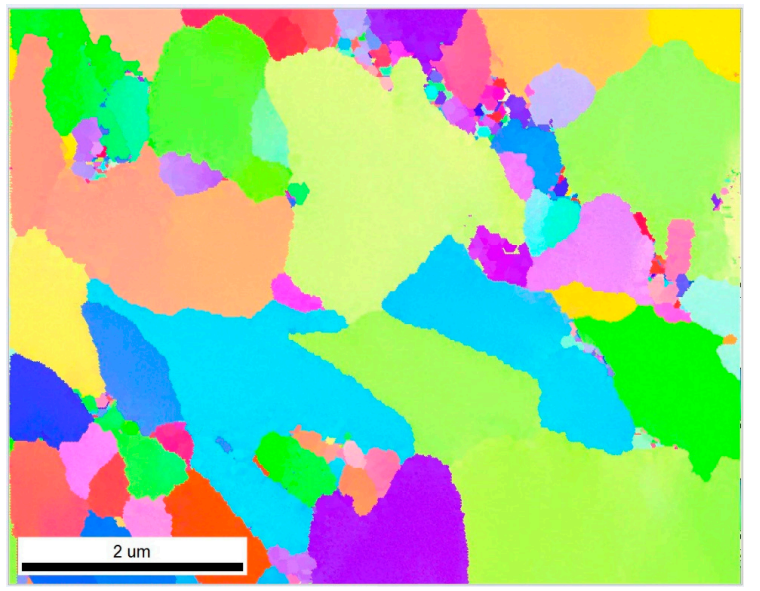

(b)

Figure 3. Electron backscattered diffraction (EBSD) inverse pole figures (IPF) of FAST consolidated $\mathrm{Fe}_{91}-\mathrm{Ni}_{8}-\mathrm{Zr}_{1}$ samples processed at $750{ }^{\circ} \mathrm{C}-30 \mathrm{~min}(\mathbf{a})$ and $750{ }^{\circ} \mathrm{C}-60 \mathrm{~min}(\mathbf{b})$.

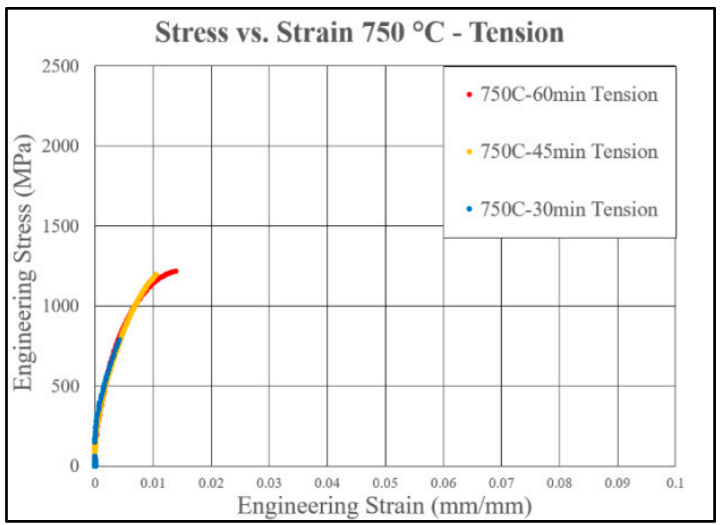

(a)

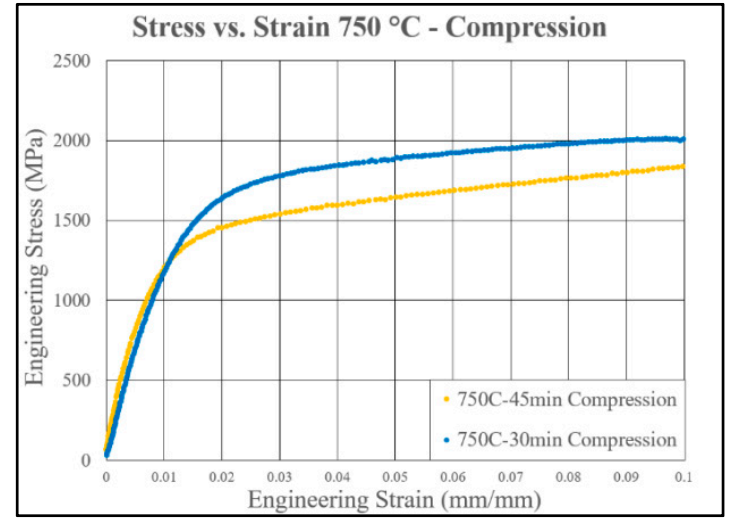

(b)

Figure 4. Tensile (a) and compressive (b) stress vs. strain results of FAST consolidation of $\mathrm{Fe}_{91}-\mathrm{Ni}_{8}-\mathrm{Zr}_{1}$ samples.

All samples were tested at room temperature, $\sim 25^{\circ} \mathrm{C}$, with tensile and compression strain rates of $8 \times 10^{-4} / \mathrm{s}$ and $3 \times 10^{-4} / \mathrm{s}$, respectively. Deformation in the tension samples consolidated at $750{ }^{\circ} \mathrm{C}$ remained almost entirely elastic, reaching failure stresses of 800 and $1200 \mathrm{MPa}$ for the 30 and $45 \mathrm{~min}$ hold times in tension, respectively. This is likely a result of the high levels of porosity observed in the samples, as evident in the SEM images shown in Figure 2. However, the material fabricated with a $60 \mathrm{~min}$ hold time showed the onset of plasticity as the curve peak started to round, thus displaying slight levels of ductility. The tension and compression data showed agreement in regard to yield stress and modulus, indicating there was no apparent tension-compression asymmetry. As evident from the compression curves for the 30 and 45 min hold times, both conditions indicated strain hardening behavior due to dislocation interaction between themselves and secondary phases. The compression samples fabricated from the $750^{\circ} \mathrm{C}-30 \mathrm{~min}$ consolidation condition displayed an average yield stress of $1100 \mathrm{MPa}$ at $1 \%$ compressive strain and each failed with maximum stress values in excess of $1800 \mathrm{MPa}$. The $750{ }^{\circ} \mathrm{C}-45 \mathrm{~min}$ samples exhibited a yield stress approximately $100 \mathrm{MPa}$ lower, but saw strain in excess of $0.19 \mathrm{~mm} / \mathrm{mm}$ (without failure), nearly double that of the corresponding $30 \mathrm{~min}$ processing condition, prior to the compression test timing out. 


\section{Discussion}

A single test was performed with a more conservative applied pressure of $18 \mathrm{MPa}\left(900{ }^{\circ} \mathrm{C}-5 \mathrm{~min}\right.$ hold time), yielding a density of around $84 \%$ of theoretical. It was quickly realized that a higher pressure would be necessary in this processing envelope (of temperature and hold time) in order to achieve full density. Higher pressures would result in additional closure of large pores early in the sintering process, further driving densification [29]. Zhaohui et al. describe the densification mechanisms of ultrafine grained copper processed via SPS following the sequence: Activation and refinement of the powder, initial formation and growth of sintering necks, followed by rapid densification and plastic deformation densification [30]. Furthermore, correctly timing the application of pressure during consolidation, i.e., applying pressure only after the maximum processing temperature is reached, can aid in achieving full densification [23]. Schwarz et al. reported achieving full densification on an $\mathrm{Al}_{5} \mathrm{CuZr}$ alloy via hot forging while maintaining a $44 \mathrm{~nm}$ grain size by applying pressure after the system reached sintering temperature [31]. Evaluating the effect of timing and increased pressures on densification and the resulting mechanical properties will be a future effort. If the hold times are extended and/or temperature is increased beyond $1100{ }^{\circ} \mathrm{C}$, it is possible that full density could be achieved. However, as a significant portion of strengthening (Hall-Petch) is a result of a refined microstructure structure, it is important to find a balance with processing conditions to maintain nano/ultrafine grains while still achieving full densification.

The density results are promising, as previous work in consolidating these powders via hot isostatic pressing yielded a maximum theoretical density of only $96 \%$ with processing temperatures ranging from $600-1000{ }^{\circ} \mathrm{C}$ [32]. The lower processing temperatures and shorter processing times required for SPS/FAST consolidations compared to HIP will result in parts which retain a finer grain structure. The ability to maintain a smaller final grain size and achieve higher density values will result in superior mechanical properties compared to other consolidation methods. Practical applications where the material would be subjected to tensile and/or fatigue stresses would be much more susceptible to residual porosity and would likely require fully dense parts for implementation. Depending on the size of the pores, they can act as sites for crack nucleation and growth, and limit the macroscopic ductility by concentrating local strain in the vicinity of the pores [33]. It remains to be seen whether the $98.6 \%$ dense samples fabricated as a part of this work have sufficiently high density for critical applications. Thus, in addition to future work on increased pressure, alternative techniques during consolidation, such as varying raw powder size distribution and two-step sintering, will be considered. Two-step sintering has been reported in the literature as a means of achieving full densification without grain coarsening. Chen and Wang report the ability to suppress final stage grain growth by exploiting the kinetic differences between grain boundary migration and grain boundary diffusion in nanocrystalline ceramics [34]. Being able to achieve full density while maintaining an ultrafine/nanocrystalline structure should yield an ODS material with properties applicable to countless applications.

\section{Conclusions}

Bulk quantities of the $\mathrm{Fe}_{91}-\mathrm{Ni}_{8}-\mathrm{Zr}_{1}$ powder were successfully synthesized with the ZOZ CM08 rotary ball mill. Utilizing the resulting powder, samples exceeding $98.6 \%$ of theoretical density were consolidated via spark plasma sintering in the FCT HP D 125.

While maintaining the relatively low processing temperature of $750{ }^{\circ} \mathrm{C}$, the hold times can be varied to minimize porosity and manipulate the resulting grain size. While the $750{ }^{\circ} \mathrm{C}$ processing temperature is sufficient for producing high density parts, the tensile ductility falls below what is necessary for a number of applications.

Tensile stresses in excess of $1200 \mathrm{MPa}$ and corresponding compressive stresses in excess of $2000 \mathrm{MPa}$ were achieved by spark plasma sintering $\mathrm{Fe}_{91}-\mathrm{Ni}_{8}-\mathrm{Zr}_{1}$ powder at $750{ }^{\circ} \mathrm{C}$. 
Author Contributions: Conceptualization, S.J.F., T.L.L., C.D.H. and K.A.D.; methodology, S.J.F., T.L.L. and K.A.D.; investigation, S.J.F., T.L.L. and A.J.R.; writing—original draft preparation, S.J.F.; writing-review and editing, S.J.F., C.D.H. and K.A.D.; visualization, S.J.F.; supervision, C.D.H. and K.A.D.; funding acquisition, K.A.D.

Funding: This research received no external funding.

Acknowledgments: The United States Army Armament Research, Development and Engineering Center (ARDEC), headquartered at the Picatinny Arsenal for use of their FAST FCT HP D 125. Army Research Lab's engineering technicians Steven Marsh and Mike Aniska for sample fabrication.

Conflicts of Interest: The authors declare no conflict of interest.

\section{References}

1. Darling, K.A.; Kapoor, M.; Kotan, H.; Hornbuckle, B.C.; Walck, S.D.; Thompson, G.B.; Tschopp, M.A.; Kecskes, L.J. Structure and mechanical properties of Fe-Ni-Zr oxide-dispersion-strengthened (ODS) alloys. J. Nucl. Mater. 2015, 467, 205-213. [CrossRef]

2. Kim, J.H.; Park, C.H. Effect of milling temperature on nanoclusters and ultra fine grained microstructure of oxide dispersion strengthened steel. J. Alloys Compd. 2014, 585, 69-74. [CrossRef]

3. Yoon, J.H.; Lee, Y.; Kang, S.H.; Byun, T.S.; Hoelzer, D.T. Effects of partial phase transformation on characteristics of 9Cr nanostructured ferritic alloy. Curr. Nanosci. 2014, 10, 47-50. [CrossRef]

4. Hoelzer, D.T.; Bentley, J.; Sokolov, M.A.; Miller, M.K.; Odette, G.R.; Alinger, M.J. Influence of particle dispersions on the high-temperature strength of ferritic alloys. J. Nucl. Mater. 2007, 367, 166-172. [CrossRef]

5. Kim, J.H.; Byun, T.S.; Hoelzer, D.T.; Kim, S.W.; Lee, B.H. Temperature dependence of strengthening mechanisms in the nanostructured ferritic alloy 14YWT: Part I-Mechanical and microstructural observations. Mater. Sci. Eng. A Struct. Mater. Prop. Microstruct. Process. 2013, 559, 101-110. [CrossRef]

6. Odette, G.R.; Alinger, M.J.; Wirth, B.D. Recent developments in irradiation-resistant steels. Annu. Rev. Mater. Res. 2008, 38, 471-503. [CrossRef]

7. Ukai, S.; Mizuta, S.; Fujiwara, M.; Okuda, T.; Kobayashi, T. Development of 9Cr-ODS martensitic steel claddings for fuel pins by means of ferrite to austenite phase transformation. J. Nucl. Sci. Technol. 2002, 39, 778-788. [CrossRef]

8. Okada, H.; Ukai, S.; Inoue, M. Effects of grain morphology and texture on high temperature deformation in oxide dispersion strengthened ferritic steels. J. Nucl. Sci. Technol. 1996, 33, 936-943. [CrossRef]

9. McClintock, D.A.; Sokolov, M.A.; Hoelzer, D.T.; Nanstad, R.K. Mechanical properties of irradiated ODS-EUROFER and nanocluster strengthened 14YWT. J. Nucl. Mater. 2009, 392, 353-359. [CrossRef]

10. Parish, C.M.; White, R.M.; LeBeau, J.M.; Miller, M.K. Response of nanostructured ferritic alloys to high-dose heavy ion irradiation. J. Nucl. Mater. 2014, 445, 251-260. [CrossRef]

11. Monnet, I.; Dubuisson, P.; Serruys, Y.; Ruault, M.O.; Kaitasov, O.; Jouffrey, B. Microstructural investigation of the stability under irradiation of oxide dispersion strengthened ferritic steels. J. Nucl. Mater. 2004, 335, 311-321. [CrossRef]

12. Miller, M.K.; Zhang, Y. Fabrication and characterization of APT specimens from high dose heavy ion irradiated materials. Ultramicroscopy 2011, 111, 672-675. [CrossRef] [PubMed]

13. Boulnat, X.; Fabregue, D.; Perez, M.; Mathon, M.H.; Decarlan, Y. High-temperature tensile properties of nano-oxide dispersion strengthened ferritic steels produced by mechanical alloying and spark plasma sintering. Metall. Mater. Trans. A Phys. Metall. Mater. Sci. 2013, 44A, 2461-2465. [CrossRef]

14. Kotan, H.; Darling, K.A.; Saber, M.; Scattergood, R.O.; Koch, C.C. Thermal stability and mechanical properties of nanocrystalline Fe-Ni-Zr alloys prepared by mechanical alloying. J. Mater. Sci. 2013, 48, 8402-8411. [CrossRef]

15. Dai, C.; Schade, C.; Apelian, D.; Lavernia, E.J. Processing techniques for ODS stainless steels. Metall. Mater. Trans. B 2018, 49, 3043-3055. [CrossRef]

16. Guillon, O.; Gonzalez-Julian, J.; Dargatz, B.; Kessel, T.; Schierning, G.; Rathel, J.; Herrmann, M. Field-assisted sintering technology/spark plasma sintering: Mechanisms, materials, and technology developments. Adv. Eng. Mater. 2014, 16, 830-849. [CrossRef]

17. Suarez, M.; Fernandez, A.; Menendez, J.L.; Torrecillas, R.; Kessel, H.U.; Hennicke, J.; Kirchner, R.; Kessel, T. Challenges and opportunities for spark plasma sintering: A key technology for a new generation of materials. In Sintering Applications; IntechOpen Limited: London, UK, 2013; pp. 319-342. 
18. Kotan, H.; Darling, K.A. Isothermal annealing of a thermally stabilized Fe-based ferritic alloy. J. Mater. Eng. Perform. 2015, 24, 3271-3276. [CrossRef]

19. Langford, J.I. Scherrer after sixty years: A survey and some new results in the determination of crystalline size. J. Appl. Crystallogr. 1978, 11, 102-113. [CrossRef]

20. Hemker, K.J.; Sharpe, W.N. Microscale characterization of mechanical properties. Annu. Rev. Mater. Res. 2007, 37, 93-126. [CrossRef]

21. Alam, M.Z.; Eastman, D.; Jo, M.; Hemker, K.J. Development of a high temperature tensile tester for micromechanical characterization of materials supporting meso-scale ICME models. JOM 2016, 68, 2754-2760. [CrossRef]

22. Srinivasarao, B.; Oh-ishi, K.; Ohkubo, T.; Hono, K. Bimodally grained high-strength Fe fabricated by mechanical alloying and spark plasma sintering. Acta Mater. 2009, 57, 3277-3286. [CrossRef]

23. Groza, J.R.; Dowding, R.J. Nanoparticulate materials densification. Nanostruct. Mater. 1996, 7, 749-768. [CrossRef]

24. Hall, E. Yield Point Phenomena in Metals and Alloys, 1st ed.; Springer: Boston, MA, USA, 1970.

25. Nieh, J.; Wadsworth, T.G. Hall-Petch relation in nanocrystalline solids. Scr. Metall. Mater. 1991, 25, 955-958. [CrossRef]

26. Kotan, H.; Darling, K.A.; Saber, M.; Scattergood, R.O.; Koch, C.C. An in situ experimental study of grain growth in a nanocrystalline Fe91Ni8Zr1 alloy. J. Mater. Sci. 2013, 48, 2251-2257. [CrossRef]

27. Kotan, H.; Darling, K.A.; Saber, M.; Koch, C.C.; Scattergood, R.O. Effect of zirconium on grain growth and mechanical properties of a ball-milled nanocrystalline FeNi alloy. J. Alloys Compd. 2013, 551, 621-629. [CrossRef]

28. Zhang, P.; Li, S.X.; Zhang, Z.F. General relationship between strength and hardness. Mater. Sci. Eng. A 2011, 529, 62-73. [CrossRef]

29. Mayo, M.J.; Hague, D.C.; Chen, D.J. Processing nanocrystalline ceramics for applications in superplasticity. Mater. Sci. Eng. A 1993, 66, 145-159. [CrossRef]

30. Zhang, Z.; Wang, F.; Wang, L.; Li, S.; Osamu, S. Sintering mechanism of large-scale ultrafine-grained copper prepared by SPS method. Mater. Lett. 2008, 62, 3987-3990.

31. Schwarz, R.B.; Desch, P.B.; Srinivasan, S.; Nash, P. Synthesis and properties of trialuminides with ultra-fine microstructures. Nanostruct. Mater. 1992, 1,37-42. [CrossRef]

32. Luckenbaugh, T.; Roberts, A.J.; Hornbuckle, B.C.; Giri, A.K.; Hammond, V.H.; Torrejon, S.M.; Darling, K.A. Large Scale Processing and Consolidation of Nanocrystalline Fe $e_{1}-\mathrm{Ni}_{8}-\mathrm{Zr}_{1}$ Alloy; POWDERMET: Las Vegas, NV, USA, 2017.

33. Bourcier, R.J.; Koss, D.A.; Smelser, R.E.; Richmond, O. The influence of porosity on the deformation and fracture of alloys. Acta Metall. 1986, 34, 2443-2453. [CrossRef]

34. Chen, I.W.; Wang, X.H. Sintering dense nanocrystalline ceramics without final-stage grain growth. Nature 2000, 404, 168. [CrossRef]

(C) 2019 by the authors. Licensee MDPI, Basel, Switzerland. This article is an open access article distributed under the terms and conditions of the Creative Commons Attribution (CC BY) license (http://creativecommons.org/licenses/by/4.0/). 